\title{
Symposium on coronary heart disease
}

\section{INT RODUCTION}

\author{
I. M.CLEAN BAIRD \\ M.D., M.R.C.P.
}

Physician and Postgraduate Medical Tutor, West Middlesex Hospital

I HAVE great pleasure in welcoming you to the first part of our Symposium on Coronary Heart Disease, which has been sponsored by the generous help of Imperial Chemical Industries. We have a twofold reason for inviting you, firstly, because we wish to present to you the experiences of an intensive coronary care unit at our own hospital, and secondly, we wish to hear the papers of our distinguished outside speakers, including Professor John Shillingford, in order that we may ourselves progress further in the techniques and management of coronary care.

It is an appropriate time to consider the problem of coronary care, because there has been a dramatic increase in the incidence of myocardial infarction in this country. In the Registrar General's statistical review for 1967, when he examines causes of death under Code 420, arteriosclerotic heart disease and all forms of coronary disease are included. This has increased by $60 \%$ for both males and females since the period 1950-52. The 'epidemic' of myocardial infarction has made this condition the most common cause for admission to acute medical wards. Many hospitals like ourselves are planning similar coronary intensive care units and it is hoped that today's papers and discussion will prove of immediate practical help. For this reason we have among our speakers an expert in the application of instrumenta $\vec{\omega}$ tion to clinical measurements, who will advise us about the problems involved in the use of sophistio cated instruments in routine hospital care. We must also remember that to provide the instruments alone is not enough - we must provide the administrations and an adequate and rapid communication system about which you will hear later in the afternoon.

Many aspects of myocardial infarction still remain to be studied, for example, should we have ambue lances as they do in Northern Ireland, who rush ouf with a special team to patients at home? Are somen patients better off at home? Because of the numerous questions you must want to ask $I$ have arrangedgato

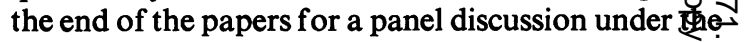
chairmanship of Professor Shillingford, where will have an opportunity to put these questions, a I hope there will be a free discussion subsequently on any aspect of these papers. Without more ado bu would like to introduce to you our first speaker whoD is one of the most important members of the Coronary Unit team, Sister Mendelssohn, who wilp talk about her nursing experiences from the practica point of view. Dr P. M. McAllen will subsequently outline our own results here in the 2-year period. since the unit opened in November 1967 at the West Middlesex Hospital. 